\title{
Epidemiological Study of Zygomatic Fractures: A Five-Year Retrospective Analysis in a Single Hospital Experience
}

\author{
AHMED A.A. ALI, M.D. \\ The Department of Plastic Surgery, Faculty of Medicine, South Valley University
}

\begin{abstract}
Background: Zygomatic complex and arch fractures remain one of the most common maxillofacial fractures. Epidemiological studies of theses fractures vary by geographic region, socioeconomic, environmental and cultural factors. Its importance is confirmed by their implication in the clinical practice and prevention.

Patients and Methods: Five-year retrospective study; from May 2015 to April 2020; was conducted on 120 patients with zygomatic fractures in our department. Fracture sites were classified into five types (I-V) based on the number of fractured processes and comminution. Data collected in a clinical sheet and analyzed using Statistical Package for Social Sciences version 20. $p$-value $<0.05$ was considered significant. Chi square test was used to compare between 2 or more qualitative variables.
\end{abstract}

Results: Patients aged from 15-78 years old and divided into 4 age groups (A-D). Group B (21-40 years) was the commonest affected. Males were predominant than females with ratio $\mathrm{M}: \mathrm{F}=(7: 1)$. Motor car accidents was the commonest etiology of trauma $(56.60 \%)$. Left sided fracture $(52.5 \%)$ was involved more than right sided one $(45 \%)$ and fracture was bilateral in $2.5 \%$ of cases. Type-IV fracture (classic tetrapod) was the commonest type reported (42 cases, 35\%). Most common fractured process was zygomatic-maxillary buttress (ZM) in 90 cases $(75 \%)$. Mandibular fracture $(15 \%)$ was the most common associated facial fractures. Most common accessed approach was the upper buccal in 80 cases $(66.6 \%)$. Access through a preexisting wound was encountered in 10 cases $(8.3 \%)$. Four-point fixation $(40 \%)$ was the commonest point fixation for these fractures. Infra orbital paresthesia (42 cases) was the most common complications encountered.

Conclusion: Zygomatic fractures have high morbidity and cost of life. Use of protective devices, strict laws and severe punishments must be implemented to reduce its frequency.

Key Words: Zygomatic fracture - Plate fixation - Epidemiology.

\section{INTRODUCTION}

The zygomatic bone has a prominent position in the maxillofacial skeleton and shares a significant portion of the orbital floor, lateral wall of the orbit, the zygomatic arch and the malar eminence. Its prominence has the ability to absorb the burden of facial injuries and so the zygomatic fractures are the second most common hospitalized maxillofacial fractures after the mandibular fractures [1,2].

Zygomatic bone has four bony attachments to the skull through its processes, which if fractured all together called classic tetrapod fracture; it also can occur as a single process fracture. They can occur as isolated fractures or can be associated with other craniomaxillofacial injuries. They are most common in young adult males [3].

The etiology of zygomatic complex fractures includes motor car accidents, assault from others, fall from height, sport-related injuries and workrelated injuries. However, the most common cause varies widely between different countries due to the differences in geographical area, socioeconomic, cultural and lifestyle factors [4].

Zygomatic complex fractures may cause deformity of the midface, sensory disturbances, disrupt mandibular and ocular function. Early diagnosis is important for perfect treatment and is directly dependent on proper initial evaluation, adequate injury assessment and timely intervention [5].

Different surgical approaches have been used for the treatment of zygomatic complex fractures. The ideal surgical approach should provide enough exposure of the fractured segments, assure less liability for further injury to vital structures and allow for acceptable cosmetic results [6].

The aim of this study was performed to retrospectively analyze the epidemiology and manage- 
ment outcomes of zygomatic complex and arch fractures treated at Plastic Surgery Department; Qena University Hospital.

\section{PATIENTS AND METHODS}

Study design and population: A retrospective study was conducted on patients admitted to Trauma Unit, Plastic Surgery Department; Qena University Hospital from May 2015 to April 2020 (5 years' duration).

Inclusion criteria: All patients with zygomatic complex and arch fractures that surgically treated.

Exclusion criteria: Patients with non-displaced fractures that conservatively treated and patients with incomplete data records.

The study was approved by the faculty ethical committee for research in human studies.

Informed consent and written releases from patients for their photos were signed.

Parameters: Data record were collected from clinical sheets with the following parameters: Gender, age, etiology of trauma, clinical presentations, computed tomographic (CT) analysis: (fracture side, fracture pattern, points of fixation, associated facial fractures), time of repair, surgical approach and complications.

Classification: Fracture sites were classified into five types (I-V) based on the number of fractured processes and comminution: Type-I: Monopod (single process), Type-II: Dipod (two processes), Type-III: Tripod (three processes), Type-IV: Classic tetrapod (four processes) and Type-V: comminuted fractures; A modification from zygomatic fracture classification system by Zingg, et al. [7].

Ophthalmic consultation: Preoperative eye examination was obtained and included: Assessment of visual acuity, pupillary function, evaluation of extraocular muscle movements, fundus examination. A forced duction test was performed when ocular movements were restricted and intraoperative exploration of the orbital floor was intended.

Surgical technique: Time of surgical intervention was tailored according to every patient's medical situation (presence of facial edema, periorbital ecchymosis or unfit for surgical intervention) and it ranged from early repair (within 12-24 hours) to delayed repair after 10 days from the occurrence of trauma.

Preoperative medications such as antibiotics (penicillin/cephalosporin) and analgesics were administrated and continued postoperatively for one week. All cases underwent surgical procedures in supine position and under general anesthesia.

Material used: KLS Martin 1.5mm and/or $2.0 \mathrm{~mm}$ plating system was used for fixation.

Statistical analysis: Data was analyzed using the Statistical Package for Social Sciences (SPSS) version 20. A $p$-value $<0.05$ was considered significant. Chi square test is used to compare between 2 or more qualitative variables.

\section{RESULTS}

A total of 120 patients were collected. The age ranged from 15-78 years old with (mean age 46.5 years old, $\mathrm{SD} \pm 44.54)$. They were divided into four age groups (A-D): Group A (0-20 years), group B (>20-40), group C (>40-60 years) and group D (>60-80 years). Group (B) was the most affected in trauma and group (A) was the least. The study included: 105 males and 15 females, the ratio of male to female was 7:1; (Table 1).

Table (1): Distribution of patients by age groups and gender.

\begin{tabular}{llccc}
\hline Age group (years) & Male & Female & Total & Percent $\%$ \\
\hline (A) $0-20$ & 10 & 1 & 11 & $9.2 \%$ \\
(B) $>20-40$ & 48 & 4 & 52 & $43.3 \%$ \\
(C) $>40-60$ & 39 & 3 & 42 & $35 \%$ \\
(D) $>60-80$ & 8 & 7 & 15 & $12.5 \%$ \\
& & & & \\
\hline Total & 105 & 15 & 120 & $100 \%$ \\
\hline
\end{tabular}

Majority of trauma was due to motor car accidents in 68 cases $(56.6 \%)$ followed by assaults from others in 39 cases $(32.5 \%)$ and lastly fall from height in 13 cases $(10.9 \%)$; shown in (Fig. 1).

In analysis of the etiology of trauma in relation to the age groups; fall from height was the commonest cause in group (A), but motor car accident was the commonest in both groups (B) and (C), while assault was the commonest in group (D); $(p-$ value <0.05) (Fig. 2). 


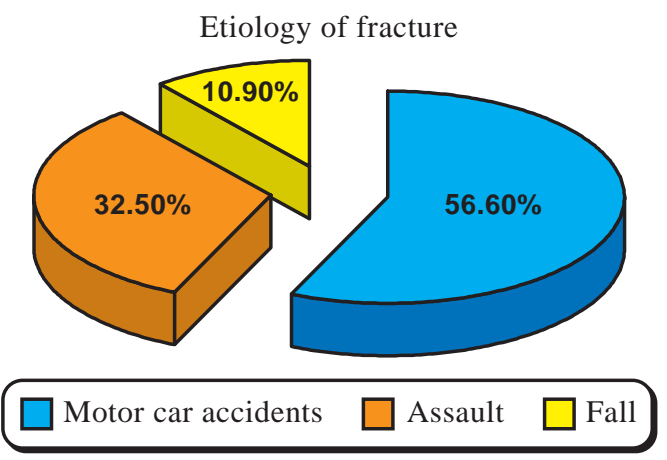

Fig. (1): Percentages of etiologies of fracture in the study population.

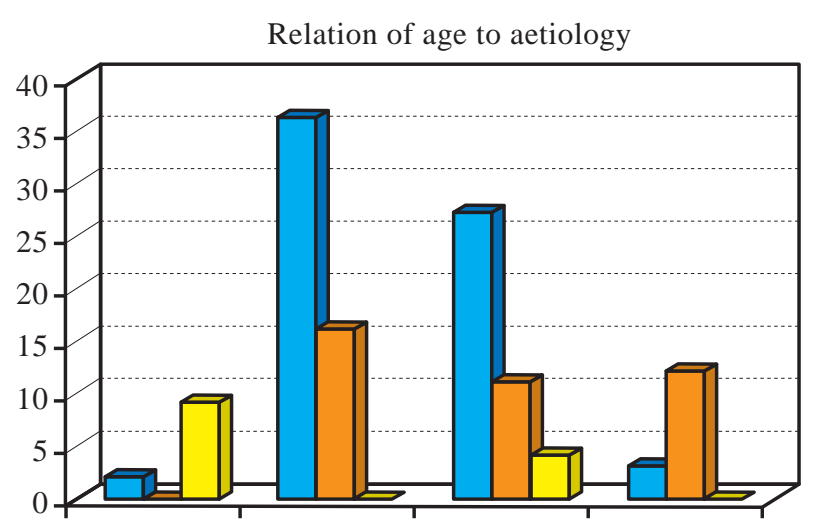

$\begin{array}{llll}\text { (A) } 0-20 & \text { (B) }>20-40 & \text { (C) }>40-60 & \text { (D) }>60-80\end{array}$

Motor car accident $\square$ Assault $\square$ Fall from height

Fig. (2): Incidence of age groups in relation to the etiology of trauma.

Analysis of the affected gender to the etiology of trauma, it revealed that in motor car accidents and assault males were predominant than females, but falls were more encountered in females, ( $p$ value $<0.05$ ).

Patients clinically presented with periorbital ecchymosis in 102 cases ( $85 \%$ ), periorbital edema in 98 cases $(81.6 \%)$, infraorbital paresthesia in 87 cases $(72.5 \%)$, subconjunctival hemorrhage in 75 cases $(62.5 \%)$, palpable step-off in 67 cases (55.8\%), enophthalmos in 25 cases (20.8\%), diplopia in 22 cases (18.3\%) and limited mouth opening in 18 cases $(15 \%)$ (Table 2 ).

Table (2): Clinical presentations in the study group.

\begin{tabular}{ll}
\hline Clinical presentation & Percentage \\
\hline Periorbital ecchymosis & $85 \%$ \\
Periorbital edema & $81.6 \%$ \\
Infraorbital paresthesia & $72.5 \%$ \\
Subconjunctival hemorrhage & $62.5 \%$ \\
Palpable step-off & $55.8 \%$ \\
Enophthalmos & $20.8 \%$ \\
Diplopia & $18.3 \%$ \\
Limited mouth opening & $15 \%$ \\
\hline
\end{tabular}

Computed tomography (CT) was the single imaging method for evaluation. Fracture of the left zygoma (63 cases, $52.5 \%$ ) was more common than the right-sided one (54 cases, $45 \%$ ) while bilateral fractures were observed in 3 cases $(2.5 \%)$.

In this study, Type-I fracture was detected in 15 cases, Type-II fracture in 21 cases, Type-III fracture in 36 cases, Type-IV fracture in 42 cases and Type- $\mathrm{V}$ in 6 cases (Fig. 3).

The most common fractured site was zygomaticmaxillary buttress (ZM) that detected in 90 cases $(75 \%)$ then zygomatic-frontal suture (ZF) in 84 cases (70\%), infraorbital rim (IR) in 72 cases $(60 \%)$ and finally zygomaticotemporal arch (ZA) in 36 cases (30\%) (Fig. 4).

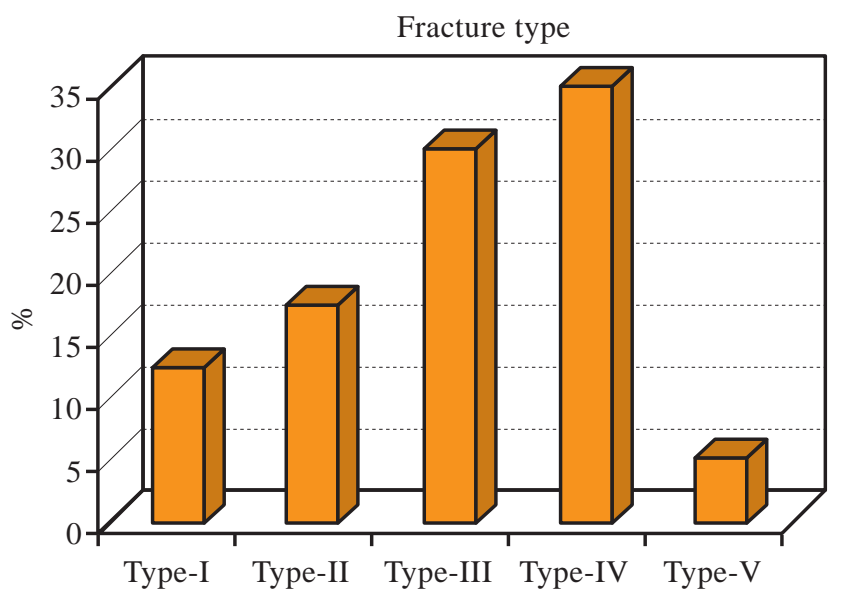

Fig. (3): Percentages of fracture types in the study population.

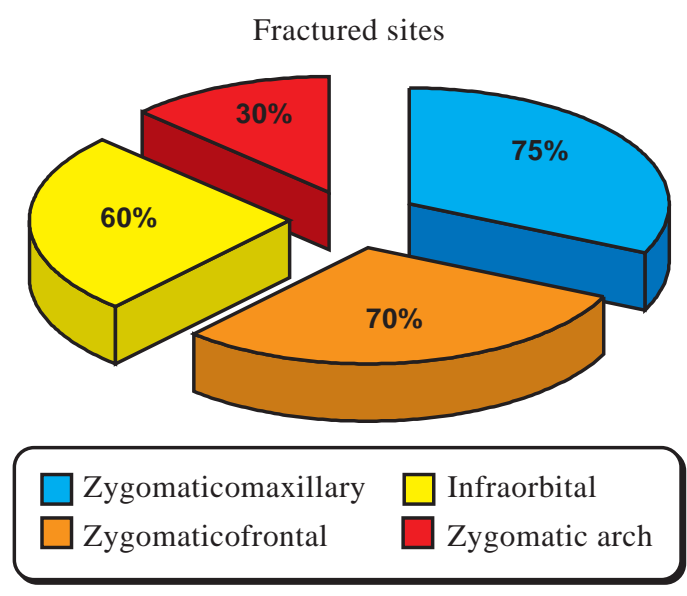

Fig. (4): Percentages of different sites of fractures.

Associated lateral orbital wall (LW) fracture was detected in 4 cases (3.3\%); Orbital floor defects were noticed in 54 cases ( $45 \%$ ) but only 24 cases (20\%) that needed reconstruction by calvarial bone graft (defect size $>1 \mathrm{~cm}$ ). 
Mandibular fractures were the most common associated facial fractures that detected in 18 cases (15\%) followed by nasal/naso-orbital ethmoid (NOE) fractures in 7 cases $(5.8 \%)$, then frontal sinus fracture in 4 cases $(3.3 \%)$ and finally maxillary Le Fort 2 fracture in 3 cases (2.5\%) (Table 3).

Table (3): Percentages of associated facial fractures.

\begin{tabular}{cc}
\hline Associated facial fractures & Percent $\%$ \\
\hline Mandible & $15 \%$ \\
Nasal/NOE & $5.8 \%$ \\
Frontal sinus & $3.3 \%$ \\
Le fort II & $2.5 \%$ \\
\hline Total & $26.6 \%$ \\
\hline
\end{tabular}

In this study, zygomatic complex fractures were repaired early in fifty patients $(41.7 \%)$ while seventy patients $(58.3 \%)$ had delayed repair for their fractures after resolution of facial edema, ecchymosis and were physically fit for surgery.

Different surgical approaches were performed and included: Upper buccal in 80 cases $(66.6 \%)$, lateral eyebrow in 75 cases $(62.5 \%)$, subciliary in 42 cases $(35 \%)$, subtarsal in 30 cases $(25 \%)$ and coronal in 28 cases $(23.3 \%)$. Access through a preexisting wound was encountered in 10 cases $(8.3 \%)$. Closed reduction of the zygomatic arch was performed through Gilles approach in 5 cases $(4.1 \%)$ and through Keens approach in 3 cases $(2.5 \%)$ (Fig. 5).

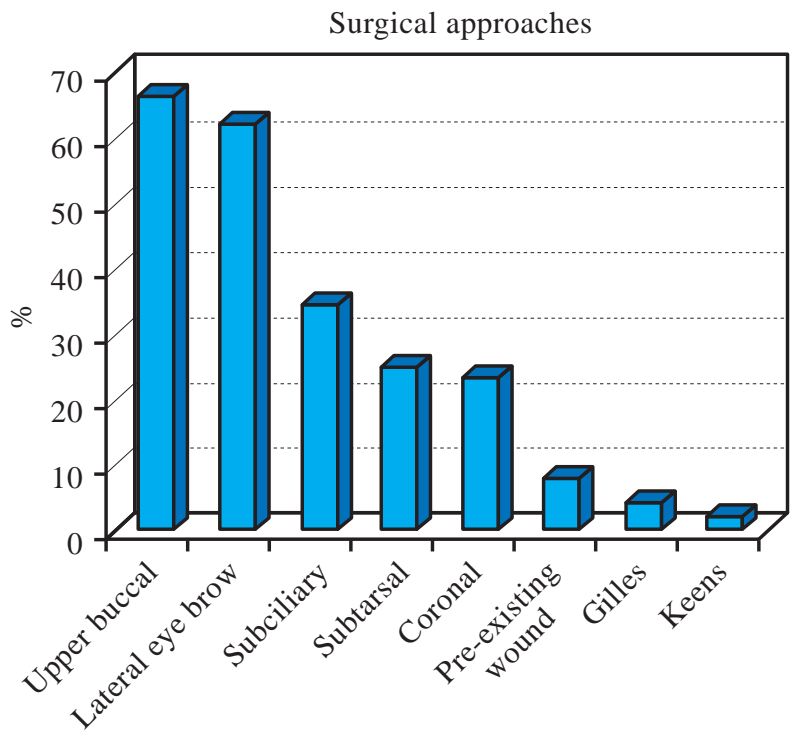

Fig. (5): Percentages of different surgical approaches.

Midface miniplate system was applied in different points of fixation according to the fracture type. One-point fixation were performed in 15 cases $(12.5 \%)$, two-point in 21 cases $(17.5 \%)$, three-point fixation in 36 cases $(30 \%)$ and fourpoint fixation (classic tetrapod fracture) was carried out in 48 case (40\%) (Table 4). Addition microplate for lateral orbital wall was applied in 3 cases $(2.5 \%)$.

Table (4): Percentages of point of fixation.

\begin{tabular}{cc}
\hline Points of fixation & Percent $\%$ for total cases \\
\hline One-point & $12.5 \%$ \\
Two-point & $17.5 \%$ \\
Three-point & $30 \%$ \\
Four-point & $40 \%$ \\
\hline Total & $100 \%$ \\
\hline
\end{tabular}

Postoperative follow-up ranged from 6 to 12 months (mean follow-up $=9$ months, $\mathrm{SD} \pm 4.24$ ). Complications included: Infraorbital paresthesia in 42 cases (35\%); (recovered within 4 to 6 months), ectropion in 12 cases (10\%); (10 cases with subciliary and 2 cases with subtarsal approach), limited mouth opening in 7 cases $(5.8 \%)$; (resolved after one month), facial asymmetry in 6 cases (5\%), diplopia in 5 cases $(4.1 \%)$ and enophthalmos in 5 cases $(4.1 \%)$.

In analysis of complications to time of surgical intervention: Persistent infraorbital paresthesia, enophthalmos and diplopia were more in late repaired cases than in cases repaired early; while ectropion and limited mouth opening was more in early repaired cases. Facial asymmetry had equivocal outcome in both repairs, $(p$-value $<0.05)$ (Fig. 6).

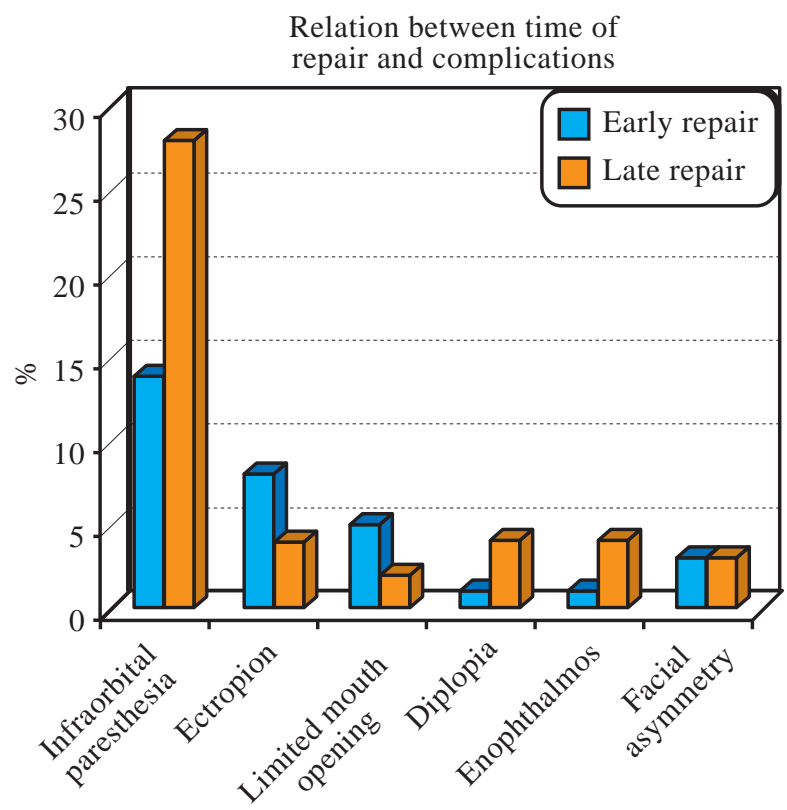

Fig. (6): Relation between time of repair and complications. 


\section{DISCUSSION}

In this retrospective analytic study, the young adult age group (21-40 years) was the most common involved group by trauma and this is explained by the high activity levels and outdoor workers in early decades of life, this finding is consistent with many studies [8-10].

Predominance of males may be due to the greater social and economic involvement of males than females especially in the developing countries, these results are similar to those presented in previous studies; however, the male to female ratio is higher in this study than in earlier ones [11,12].

Motor car accident was the most common cause of zygomatic complex fractures followed by assaults and lastly fall from height. In Egypt; like other developing countries; motor car accidents still remain the main cause of trauma. These results are compatible with most studies as motor car accidents are frequently seen as the most frequent cause of maxillofacial trauma in many developing countries [13-15].

Other studies showed that assaults from others remain the main cause of trauma, as in developed countries, this could be explained by high unemployment rates and alcohol consumption [16,17]. Meanwhile, strict law road legislations, use of seat belts and helmets decrease incidence of motor car accidents in these countries. Other studies reported that fall was the predominant cause of trauma [18].

Analysis of the relation between age groups and etiology of trauma showed that motor car accidents was the commonest etiology of trauma in young and middle age groups. This can be attributed to the careless behavior of driving small vehicles like motorbike and Tok-tok (three wheel auto rickshaw) in that age groups that ends in major accidents. Assaults from others were the second commonest cause in early ages with increasing activities and outworking, but with advancing age, fall becomes the commonest.

The study reported that left sided fracture was more common than right sided one and similar findings were recorded in other studies [19]. Bilateral zygomatic fractures observed only in 3 cases and this rare entity was recorded in previous studies [20,21]. Zygomaticomaxillary buttress was the most common fractured site in the study, many studies had the same findings [15]. However, other studies showed that zygomaticofacial suture was the commonest site [22].
Fracture sites and patterns are different from one study to the other. In this study, the commonest was classic tetrapod fracture then tripod, dipod and finally monopod fractures.

Incidence of associated maxillofacial fractures reported that mandibular fractures were the most common fracture. As in most studies, mandibular fracture still remain the commonest fractures encountered with zygomatic complex [22].

The criteria of approach were based on the location and type of fractures. These approaches provided the best result with minimal complications such as pain, nerve injury, cosmetic disfigurement. Coronal approach was reserved for displaced arch fractures and comminuted cases. Gilles approach and Keens approach performed in closed reduction of the zygomatic arch fracture.

Variable number of points of fracture fixation performed: 4-point fixation was the commonest followed by 3 -point fixation, 2-point fixation and finally 1 - point fixation. Many studies performed to analyze the differences between 2-point fixation and 3-point fixation and these studies based on fracture pattern, amount of displacement, intraoperative stability, avoidance of external scars and plate cost for the patients. These studies revealed that according to these factors and surgeon preference, the same postoperative results would be obtained [23,24].

Complications of treatment of zygomatic complex and arch fractures are relatively uncommon. The most common complication is paresthesia of the cheek due to infraorbital nerve affection. In this study, most patients presented with paresthesia of the infraorbital nerve in 87 cases and postoperatively in 42 cases. Proper fracture reduction and fixation were important steps in the recovery of infraorbital nerve sensory disturbances. So, postoperative persistent paresthesia may be due to improper fracture reduction or severe nerve injury [25].

Our patients recovered within 4 to 6 months from infraorbital paresthesia. Recovery of neurosensory affection of infraorbital nerve may take up to 12 months and in a prospective study done by Folkestad and Granström, [26] 67\% of the patients still have infraorbital nerve paresthesia after 1 year of treatment, in spite of proper reduction and fixation. This raises the questions of whether the paresthesia is due only to the trauma or also to the tissue manipulation during the operation [27].

Limited mouth opening (trismus) is due to displacement of fractured zygomatic arch causing 
mechanical impingement of the coronoid process of the mandible. In this study only 18 cases presented with trismus and postoperatively, there were only 7 cases had trismus, this may be due to postoperative edema. They resolved after 1 month with physical exercise and antiedematous medications.

Eye manifestations such as enophthalmos, diplopia and ectropion were presented in our study to some extent. Preoperative enophthalmos was detected in 25 cases and in postoperative followup, there were only 5 cases that had enophthalmos. This may be attributed to periorbital fat atrophy.

Preoperative diplopia was found in 22 cases (18.3\%) and postoperatively diplopia persisted in in 5 cases $(4.1 \%)$. Another study by Calderoni revealed that $7.1 \%$ of patients presented with persisting diplopia after treatment [6]. In their studies on orbital floor fractures after treatment with orbital floor implant, Zingg et al., stated that diplopia persisted in $17 \%$ of cases and enophthalmos in $11 \%$ of cases [7]. However, in other study the diplopia was resolved after the surgery [28].

Postoperative ectropion was encountered in 10 cases due to subciliary incision that was temporary and resolved with anti-scar treatment and massage. Only two cases required surgical correction. Also, with subtarsal incision two cases had temporary ectropion that resolved with anti-scar treatment. Incidence of ectropion due to subciliary incisions vary considerably.

Manson and Iliff reported 10\% incidence of temporary ectropion using a skin muscle flap [29].

Meanwhile, Wray et al., reported $10 \%$ incidence of permanent ectropion that required surgical repair [30]. Pospisil reported $18 \%$ temporary ectropion but only $4 \%$ was permanent [31].

Usually, delayed repair allows for the resolution of soft tissue oedema such that surgical incisions may be more easily located in pre-existing skin creases, reducing the incidence of unacceptable scarring. However, surgical delay leads also to increased difficult manipulation due to callus formation at bone ends, which may lead to an increased incidence of inadequate fracture reduction [32].

In this study, outcomes and complications of zygomatic fractures were relatively different in early and delayed repaired cases. Facial asymmetry had equivocal outcome in both time of repairs. However, persistent infraorbital paresthesia, enophthalmos and diplopia were more in late repair than early repair; while ectropion and limited mouth opening was more in early repaired cases.

In another study, there were no significant association between delay of repair and incidence of postoperative facial asymmetry, trismus but statistically significant associations were found between delay and facial scarring and radiographic outcome [33].

The limitation of this study is its retrospective character, which can lead to bias. However, this limitation can be clearly overcomed by recording large number of patients that could be evaluated retrospectively. Other limitation is the inadequate data records, so many cases were excluded from the study.

\section{Conclusion and recommendations:}

Zygomatic complex fractures remain one of the most common maxillofacial fractures and result frequently from motor car accidents. The highest prevalence is in young male patients and commonly is associated with mandibular fractures. Rigid fixation with plates and screws is the standard method for fixation and gets more stability. Epidemiological studies need larger data scale for more accurate evolution. Multicentric study is recommended to give more valuable results that can be used for legal and curative action plans in our country.

\section{Conflict of interest: Non declared.}

Fund: None.

\section{REFERENCES}

1- Karthik Ragupathy and Sanjay Pasupathy: An epidemiological study of zygomatic complex and zygomatic arch fractures in a tertiary hospital: A retrospective study. Journal of Oral Medicine, Oral Surgery, Oral Pathology and Oral Radiology, 3 (1): 1-4, 2017.

2- Chattopadhyay P.K. and Chander M.: Management of Zygomatic Complex Fracture in Armed Forces. Med. J. Armed Forces India, 65 (2): 128-30, 2009.

3- Ungari C., Filiaci F., Riccardi E., Rinna C. and Iannetti G.: Etiology and incidence of zygomatic fracture: A retrospective study related to a series of 642 patients. Eur. Rev. Med. Pharmacol. Sci., 16 (11): 1559-62, 2012.

4- Obuekwe O., Owotade F. and Osaiyuwu O.: Etiology and pattern of zygomatic complex fractures: A retrospective study. J. Natl. Med. Assoc., 97 (7): 992-6, 2005.

5- Yamamoto K., Matsusue Y., Horita S., Murakami K., Sugiura T. and Kirita T.: Clinical analysis of midfacial fractures. Mater Sociomed., 26 (1): 21-5, 2014.

6- Calderoni D.R., Guidi Mde C., Kharmandayan P. and Nunes P.H.: Seven-year institutional experience in the 
surgical treatment of orbito-zygomatic fractures. J. Craniomaxillofac. Surg., 39 (8): 593-9, 2011.

7- Zingg M., Laedrach K., Chen J., Chowdhury K., Vuillemin T., Sutter F. and Raveh J.: Classification and treatment of zygomatic fractures: A review of 1,025 cases. J. Oral Maxillofac. Surg., 50 (8): 778-90, 1992.

8- Zaleckas L., Pečiulienẻ V., Gendvilienẻ I., Pūrienẻ A. and Rimkuviené J.: Prevalence and etiology of midfacial fractures: A study of 799 cases. Medicina (Kaunas), 51 (4): 222-7, 2015

9. Tripathi G.M., Sharma D., Gaharwar A.P.S., Gupta R., Shukla D. and Shukla V.: Analysis of Prevalence and Pattern of Zygomatic Complex Fractures in North-Eastern Part of Madhya Pradesh, India. International Journal of Contemporary Medical Research., 3 (7): 1878-81, 2016.

10. Punjabi S.K., Habib-ur-Rehman, Ali Z. and Ahmed S.: Causes and management of zygomatic bone fractures at Abbasi Shaheed Hospital Karachi (analysis of 82 patients). J. Pak. Med. Assoc., 61 (1): 36-9, 2011.

11- Mijiti A., Ling W., Tuerdi M., Maimaiti A., Tuerxun J., Tao Y.Z., Saimaiti A. and Moming A.: Epidemiological analysis of maxillofacial fractures treated at a university hospital, Xinjiang, China: A 5-year retrospective study. J. Craniomaxillofac. Surg., 42 (3): 227-33, 2014.

12- Gaddipati R., Ramisetti S., Vura N., Reddy K.R. and Nalamolu B.: Analysis of 1,545 Fractures of Facial RegionA Retrospective Study. Craniomaxillofac. Trauma Reconstr., 8 (4): 307-14, 2015.

13- Başaran K., Saydam F.A., Pilancı Ö., Sağır M. and Güven E.: Optimal treatment of zygomatic fractures: A singlecenter study result. Kulak Burun Bogaz Ihtis, 26 (1): 4250, 2016.

14- Naveen Shankar A., Naveen Shankar V., Hegde N. and Prasad R.: The pattern of the maxillofacial fracture sea multi-center retrospective study. J. Craniomaxillofacial Surg., 40: 675-79, 2012.

15- Nordin R., Rahman N.A., Rashdi M.F., et al.: Oral and maxillofacial trauma caused by road traffic accident in two university hospitals in Malaysia: A cross-sectional study. J. Oral Maxillofac. Surg. Med. Pathol., 27: 166$171,2015$.

16- Trivellato P.F., Arnez M.F., Sverzut C.E. and Trivellato A.E.: A retrospective study of zygomatico-orbital complex and/or zygomatic arch fractures over a 71-month period. Dent Traumatol., 27 (2): 135-42, 2011.

17- Lee K.H., Snape L., Steenberg L.J. and Worthington J.: Comparison between interpersonal violence and motor vehicle accidents in the etiology of maxillofacial fractures. ANZ J. Surg., 77 (8): 695-8, 2007.

18- Adam A.A., Zhi L., Bing L.Z. and Zhong Xing W.U.: Evaluation of treatment of zygomatic bone and zygomatic arch fractures: A retrospective study of 10 years. J. Maxillofac. Oral Surg., 11 (2): 171-6, 2012.
19- van Hout W.M., Van Cann E.M., Koole R. and Rosenberg A.J.: Surgical treatment of unilateral zygomaticomaxillary complex fractures: A 7-year observational study assessing treatment outcome in 153 cases. J. Craniomaxillofac. Surg., 44 (11): 1859-1865, 2016.

20- Gadre P.K., Bhola N., Borle R. and Gadre K.S.: Isolated bilateral zygoma fracture: A rare entity. J. Craniofac. Surg., 24 (4): 1498-500, 2013.

21- Ramanathan M. and Cherian M.P.: Isolated bilateral zygomatic complex and arch fracture: A rare case report. Craniomaxillofac Trauma Reconstr., 3 (4): 185-8, 2010.

22- Forouzanfar T., Salentijn E., Peng G. and van den Bergh B.: A 10-year analysis of the "Amsterdam" protocol in the treatment of zygomatic complex fractures. J. Craniomaxillofac. Surg., 41 (7): 616-22, 2013.

23- Rana M., Warraich R., Tahir S., Iqbal A., von See C., Eckardt A.M. and Gellrich N.C.: Surgical treatment of zygomatic bone fracture using two-points fixation versus three-points fixation: A Randomised Prospective Clinical Trial. Trials., 12: 13-36, 2012.

24- Parasher A., Sharma R.K. and Makkar S.: Rigid internal fixation of zygomatic fractures: A comparison of 2-point and 3-point fixation. Indian J. Plast. Surg., 40 (01): 1824, 2007.

25- Prachur Kumar, Godhi S., Lall A.B. and Ram C.S.: Evaluation of Neurosensory Changes in the Infraorbital Nerve following Zygomatic Fractures. J. Maxillofac. Oral Surg., 11 (4): 394-9, 2012.

26- Folkestad L. and Granström G.: A prospective study of orbital fracture sequelae after change of surgical routines. J. Oral Maxillofac. Surg., 61 (9): 1038-44, 2003.

27- Benoliel R., Birenboim R., Regev E. and Eliav E.: Neurosensory changes in the infraorbital nerve following zygomatic fractures. Oral Surg. Oral Med. Oral Pathol. Oral Radiol. Endod., 99 (6): 657-65, 2005.

28- Khreisat M.: Diplopia in zygomatic-complex fracture. Pak Oral Dental J., 31: 27-32, 2011.

29- Manson P. and Iliff N.: Orbital fractures. Facial Plast Surg., 5: 243-259, 1988.

30. Wray R.C., Holtmann B., Ribaudo J.M., et al.: A comparison of conjunctival and subciliary incisions for orbital fractures. Br. J. Plast. Surg., 30: 142-145, 1977.

31- Lacy M.F. and Pospisil O.A.: Lower blepharoplasty postorbicularis approach to the orbit: A prospective study. Br. J. Oral Maxillofac. Surg., 25: 398-40, 1987.

32- Hurrell M.J., Borgna S.C., David M.C. and Batstone M.D.: A multi-outcome analysis of the effects of treatment timing in the management of zygomatic fractures. Int. J. Oral Maxillofac. Surg., 45 (1): 51-6, 2016.

33- Rahman R.A., Ghazali N.M., Rahman N.A., Pohchi A. and Razak N.H.A.: Outcome of Different Treatment Modalities of Fracture Zygoma. J. Craniofac. Surg., 31 (4): 1056-1062, 2020. 